\title{
Talk-back television: The Western Australian experience
}

\author{
James C. Lange \\ Golden West Network
}

\begin{abstract}
Educational television has only just begun in Western Australia, despite having been around for nearly thirty years. The Golden West Network offers free access to a satellite television system that covers the entire state. Coupled with a telephone return, it allows an interactive method of increasing educational productivity both for on-campus instruction and distance education. The main barriers to success are lack of budget, along with the old standbys of ignorance, fear, apathy and lack of encouragement.
\end{abstract}

Education is a form of broadcasting: one-to-many transmission of information, with limited feedback. Traditionally, higher education has been an interpersonal, face-to-face broadcast system, where an expert lectures and students listen. Teacher-to student communication is seen as primary, studentto-teacher is seen as secondary and student-to-student communication is ignored.

Distance education limits the student-to-teacher link and often prevents any student-to-student communication at all. Seeing the effect of their absence has made distance educators more aware of the importance of these kinds of communication to the educational process.

Recently, society has begun to consider constraints beyond distance as barriers to on-campus education, such as physical handicap, or the isolation of the parent who is home-bound by small children. At the same time, distance education systems around the world have demonstrated the ability to teach twice the students at half the cost of on-campus instruction.

Unfortunately, the application of communication technologies which can improve the quality and reduce the cost of education at a distance, and provide it in a more interactive way, have been slow to come to Australia. Although our School-of-the-Air was a world pioneer in interactive distance education, the rest of the world is now using newer technology to pass us by in both quality and cost-efficiency.

The advent of AUSSAT, Australia's domestic satellite system, has sparked a renewed interest in telecommunications technology for distance education in Australia. However, beyond providing truly state-wide or nation-wide coverage for the first time in the country's history, AUSSAT offers nothing that can't be done over land-lines or radio, which have been available to us for several decades. The main reasons why "new" educational techniques being 
touted for AUSSAT are not already in common use in Australia are ignorance, fear, apathy, and lack of encouragement on the part of our academics and administrators.

Most academic staff had little contact with information and communication technologies in their own education. The resulting ignorance breeds fear that the new technology will somehow take over their jobs. From this fear arises a general opposition to adoption of any technological solution to teaching problems. Some of this fear is irrational, but some is justified. At the same time, most academics are already working quite hard at their current jobs. Without incentives and rewards, using new technology becomes a voluntary overload for the few dedicated idealists who are constantly committed to finding a better way to teach. The mainstream academics, seeing this extra effort go completely unrewarded, justifiably consider the pioneers fools.

The new technology will require significant funds to establish, but the purchase of hardware will not guarantee that any use is made of it, as the numerous under-used educational television and radio studios around the country indicate. They are not idle because they are not effective, nor because they are too costly. They are idle because use of them simply does not count in the performance measures by which academics are judged. As I have already published specific suggestions as to how technological ignorance, fear, apathy and lack of encouragement might be overcome, I will not go into them again in this paper. Instead, I will concentrate on a current example of telecommunications technology in support of education. Before doing so, however, I'd like to make one point about educational technology.

\section{Basic rule for educational technology}

A good rule of thumb for education technology is: don't use it unless $90 \%$ of your audience are familiar with it and have easy access to it. Neither students nor teachers are highly technologically literate. They do not take well to technologies which are not in everyday use around their house or their office. Obviously, that is advice for the day-to-day operator, not the leading-edge innovator. It is advice for those who want an immediately successful, on-going program, not for those who are willing to fail a few times before winning through.

This rule-of-thumb limits us considerably. For example, we can forget computers, unless we are teaching computer subjects or subjects that everyone already accepts must have computers to get the job done.

If we eliminate new or strange technology, what are we left with? Nothing, really. Telephones, radios and television sets are familiar to the students, but loud-speaking terminals, microphones and cameras are not familiar to the teachers. That may sound overly pessimistic, but it points up the key fact that $\mathrm{NO}$ educational technology is going to succeed unless we invest a considerable amount on training the teacher in how to use it.

However, rather than just state the obvious and sit down, I suppose I should go one step farther and discuss the three bits of technology that are familiar to students: telephones, radios and television sets. These can succeed in a limited way because there are a number of teachers who have spent their own time and money to become familiar with the technology. 
Telephone conferencing is an inexpensive means of adding interaction to distance education. Although, at first glance, it would seem that an audio-only system loses a great deal in comparison, face-to-face instruction, this is because we are not familiar with the technology. Those who have used it for extended periods will assure you that all of the inter-personal interplay that takes place in face-to-face groups is also present in audio-only groups. People learn to use conventions that replace the visual clues.

Radio is more difficult to use than telephones, because it has been sold as a one-way medium. The instructor carries the entire burden of the conversation, a situation made worse by the fact that all other uses of radio are passive, and we expect most of them to be entertaining. In effect, we are asking the instructor to compete with very highly paid professional entertainers, and we shouldn't wonder that they come off badly in comparison.

Combining the radio and telephone is common practice in commercial entertainment radio. I dare say that there is a popular "talk-back" show in every major city of the world. It puzzles me why this approach has not been tried for education. Not only would it reduce the burden on the instructor/presenter, but it would improve the listenability of the program for the audience. Everyone finds it easier to attend to a two-way interchange that they are personally involved in, than to a one-way theoretical harangue. Perhaps the reason this technique has not been used in educational radio is that academics would rather not know who are, and who are not, really out there listening.

Naturally, for many education tasks, a visual element is needed to demonstrate or reinforce a complex concept. For most of these tasks, a still picture is quite enough. Audio signals can be enhanced by digital transmission of slow-scan television (which acts as a long-distance photo-copier), by electronic blackboards or by computer graphics. Thus text, pictures and graphics can be broadcast, providing that students or study centres have access to micro-computers, modems, printers facsimile machines and SSTV terminals.

Bearing in mind the rule-of-thumb about familiar technology, we can forget these enhancements. They simply are not available in the normal students home. They must be restricted to delivery between study centres, which are properly equipped with people to make the use of the technology easy for both teacher and student. And the number of study centres with all of this equipment is small indeed.

There is, however, one kind of communications technology that can provide voice, visual and interaction: talk-back television. Television reaches every student home, and nearly every student home has access to a telephone. (In less wealthy countries, this application will also need to be restricted to study centres.)

Television broadcasting is used to deliver entire courses of study in over 50 countries. The technology is long past the experimental stage. Television has been successful because it offers maximum impact; engaging the eyes and ears with sight, sound and motion. 
The current generation of students have grown up with television, using it constantly as both a source of entertainment and information. On the positive side, students see televised instruction as familiar, comfortable and pleasant. On the negative side, they want televised education to be similar to commercial broadcasting: a passive medium which requires no intellectual work to assimilate, and which must meet the slick production standards of entertainment.

The easiest way to overcome this is not by spending thousands of dollars on productions that are equally slick, but by adding a talk-back circuit to make the program a two-way conversation that is more interesting and less expensive. Commercial broadcasters should be willing to donate low-audience time for such programs, as they will reap good public relations rewards from a portion of their schedule that now loses money anyway. Indeed, the regional broadcaster in Western Australia is already doing so.

\section{Educational television in Western Australia}

On the 4th July, 1984, Paul Bendat, managing director of the Golden West Network and I, then working for the University of Western Australia, invented Education Television Broadcasting for Western Australia.

It may sound odd to boast of inventing a concept that was already 30 years old at the time, especially when the Australian Broadcasting Corporation had been carrying educational broadcasts since its inception and the Western Australian Education Department had been running a loan-video Programme for several years. However, considering a lack of progress in the medium, it is a fair statement.

The $\mathrm{ABC}$ has always been a national service. Its programs do not and cannot take into account the differences between the curricula from state to state. To do so would require the $\mathrm{ABC}$ to produce seven different versions of its educational broadcasts, something that is beyond even their massive resources.

Of course, the ABC could have broadcast state-specific programs produced by the state education authorities. Indeed, they were committed to doing so in theory. In practice, state-produced programs were required to meet $A B C$ standards. The ABC concept of standards went far beyond objective measures of technical quality, to include production values and even educational approach. Thus it was not unusual for local educational producers to have to reject a program as substandard, and then to find commercial broadcasters willing to pay for the privilege of putting the show to air. While ABC's top management, both national and state, reiterated a willingness to cooperate with state educators, the educational producers within the ABC saw outside educational producers as competition that might cut jobs and resources devoted to education within the ABC. With the advent of the satellite, it was clear that the $\mathrm{ABC}$ would become even more national, even more Sydney based, and even less responsive to the differing needs of the differing states.

Thus, the Golden West Network found an eager audience when it offered free access to educational programs. GWN was applying for the licence to deliver Remote Commercial Television Services via the satellite, and wanted to begin some experiments over their terrestrial network so that they would be ready to 
begin if they got the licence. GWN did get the licence, and on the 20th of October, 1986, the first educational program was broadcast via satellite, to every television in the state outside of Perth and Geraldton. But that is getting ahead of the story.

On July 4, 1984, I was running a conference on AUSSAT and Education, with experts from across the country presenting papers on the benefits that this new telecommunications resource had to offer. Paul Bendat, while being impressed by the richness of ideas and the thoroughness of the research that had been done on similar systems overseas, noticed that most of the papers were theoretical. With a few notable exceptions, no one had actually been able to do anything.

Paul and I met to discuss the possibilities, and by early July invited representatives from the State education department and the four institutions of higher education to a meeting where free access to television time was offered. The first ten-week experimental term went to air on September 24th, barely three months after the idea had been proposed. That is unheard of speed for educators, especially since it involved cooperative effort among seven different agencies, ranging from preprimary to postgraduate education.

That first experiment presented just 24 hours of programming over the ten weeks, or about 30 minutes per day, but it was the first time that schools and students in Western Australia had access to programs designed specifically for them and presented at times that fit specifically within their own curriculum. The experiment had several other national firsts.

Since 1979, when Australia's domestic satellite became a serious gleam in the government's eye, people had been talking about using down-time (midnight to dawn) for down-loading educational programs (broadcasts designed to be recorded on VCR machines that had been pre-set to turn on for the scheduled delivery). It had been talked about so often that it had become a common assumption, but no one had actually tried to do it until the Western Australian College of Education used the Golden West Network to broadcast video tapes to distant students in support of their Bachelor of Education course from 12:30 am to 1:00 am.

Similarly, educators had been talking about adding a visual component to School-of-the-Air, Australia's innovative open classroom conducted via shortwave (HF) radio. But no-one had ever tried it until the Western Australian Distance Education Centre used the Golden West Network to conduct interactive sessions on the mathematics problems facing distant students in the coming Tertiary Admission Examinations. Students were able to ring the station and ask the instructors direct questions, and then watch the answers being worked out on the studio white-board.

With the advent of the Remote Commercial Television Service, this kind of education now covers the entire state of Western Australia - an area 1.3 times the size of the United States or $90 \%$ of Western Europe. The programming content has grown to 70 hours per term, or about 1.5 hours per day, and there are now ten participating institutions. The most recent highlight was the October 22nd interactive program on Nursing in the Outback, which allowed Health Department experts and administrators to talk with nurses and the general public in isolated areas. Calls came from nurses all over the state, 
including Balgo Mission, deep in the Great Sandy Desert, via HF radio to the Derby Royal Flying Doctor base station and then via telephone to the studio.

The educational service has been extremely well received by the teachers in isolated Western Australian schools, who have now come to count on GWN's educational broadcasts as a regular part of the resource repertoire. They are ecstatic about the ability to call on the same kind of resources that their city colleagues have, especially since it is now delivered at just the right time to fit into their curriculum.

Indeed, after only six terms of experimentation, we have already entered the complaints stage. Teacher and students complained that it was difficult to get access to the program schedule, since only one wall-chart was sent to each school. We remedied this by arranging to have the schedule printed in a local newspaper called the Western Mail, and by putting the schedule on GWN's videotex service.

\section{Future prospects}

It may sound like everything is rosy for educational television in Western Australia, but I am afraid that the budget to support these efforts has not matched the enthusiasm of the participants.

The Education Department of Western Australia needed about $\$ 300,000$ in this year's budget to make their educational broadcasting effort fully operational. This included about $\$ 100,000$ for satellite receivers at distant schools, $\$ 100,000$ for program acquisition and $\$ 35,000$ for extra production equipment, as well as two new staff.

The State government agreed, in principle, to provide this new money, but cabinet referred it to the budget committee. This is a very tight year for the State government budget, and the result was that the Education Department got ZERO dollars for educational television and the Audio-Visual branch, far from getting two new staff, were cut by five instead.

The head of the Audio-Visual Branch, Bob Rodgers, intends to continue education department involvement, but he will have to squeeze the money out of other existing programs. This means that teachers and students will see a reduction in total EDTV time, fewer new programs and more repeats than they have been accustomed to in the past. However, the budget crunch may also act as an impetus to further development. The EDTV coordinator, Trish Hurley, has noticed a growing interest in using the system for in-service training and for dissemination of changes in curriculum or procedures, since there is simply not enough money to conduct this necessary business face-toface.

Higher education institutions have had a much more difficult time in coming to grips with educational television. This is due to the fact that teaching, while nominally an equal third of staff evaluation, in fact is considered to be the least important aspect of academic productivity. Murdoch University has a large studio, but little equipment, less staff and next to no production budget. Nonetheless, they have struggled together to put up a program for each week of EDTV, and have started to budget a small amount for the service. Similarly limited, the Western Australian Institute of Technology has developed a 
streamlined production system for EDTV programs which has allowed them to stay in the service even though operating on a shoe-string.

Perhaps the most disappointing is the University of Western Australia, whose output has been limited to a couple of public relations pieces each semester, with no serious academic content. University Extension has plans to begin mounting "telecourses" in 1987 which will support themselves from student fees, but they are having a hard time getting their programs together.

The bright spot on the horizon is the Western Australian College of Advanced Education. WACAE has five campuses, about to grow to six, as well as a number of study centres around the state. Tele-teaching by satellite looks to have immediate economic benefit for them and they plan to begin using four hours per week for lectures in the second tern of 1987 . This will be a $700 \%$ increase, but should mean no increase in production costs, since they will be dealing with live delivery rather than tape productions. A live class demands about two hours of production time for every hour on air, compared to a minimum of ten-to-one for an in-studio tape or twenty-to-one for productions including outside shots.

Although the benefits are worth the price, educational television does cost money and does require staff time to produce. Education authorities in Western Australia have learned how to use the medium effectively and have learned to work together in spite of cross-sectoral or inter-institutional jealousies and rivalries. Educational television broadcasting is well-and-truly launched in Western Australia. However, whether they can continue depends on the participants' success in the budget process.

\section{Who pays for education}

Australia has an interesting system of higher education, whereby the working class pays for a free university education for the upper middle class. I am not quite sure why this is, perhaps we feel that the upper middle class already pay too much in taxes, so they should not be asked to contribute to the system which is needed to gain the skills to pay those taxes. Certainly, we try to play down any system of scholarships based on need, as that exposes just how few needy there are in the system.

Whatever the reason, many governments do not agree with charging the student directly for the cost instruction, via tuition fees. Nevertheless, the cost of education is always divided between the student and the institution. For example, in every country in the world, the student must pay for some consumables (textbooks, paper, laboratory materials, or the like) and for minor equipment (slide-rule, pens, calculator, typewriter etc.) Even where tuition fees are the norm, the institution normally picks up the cost of providing physical plant, library and administrative personnel out of endowment or other non-student income.

The ever tightening budgets available to public education indicate that we must ask the beneficiaries to carry some of the costs or else be willing to see a fall in quality, student numbers, or both.

For talk-back television, success may depend on putting some of the costs on the students who benefit. As a minimum, the cost of the telephone call should 
be put onto the participating student or study centre. This reduces the apparent cost to the central administration, whether within a school, a school system, a state or a country.

Whoever pays, we are going to need some new funds to get educational telecommunications started, whether we want systems that use voice, video or data. We will need money for equipment, transmission capacity and teacher training. However, care must be taken that funds are only supplied as "seed money" for trials designed to form the nucleus of a future operational system. If such a trial can demonstrate that the system is cost-effective, funding will quickly be forthcoming to continue it. Funds should not be wasted on simple demonstrations, as these systems tend to be discarded after production of an evaluation document that is filed and forgotten.

\section{Summary and conclusion}

New technology can help cut costs and improve quality, equity and participation in distance education, with major benefits for rural residents, working students, women with small children and the physically handicapped. Using these same distance education techniques in the face-toface classroom can increase productivity, resulting in more students receiving the same quality of education at the same cost.

However, unless academics and administrators are given training in new educational technologies, they will remain a source of opposition and possible sabotage. Without incentives and rewards for participation, most academics will not use technological solutions regardless of how much they might cut institutional costs or improve the quality of teaching and research.

The choice of technology, medium and carrier is application specific with different goals demanding different systems. However, talk-back radio and television are well-proven systems that are simply waiting to be exploited.

We think that it is time for talk-back television and radio to take up where School-of-the-Air left off. Without encouragement from the state and national governments, this next step is unlikely in Australia, and neighbouring countries are already taking over our initial lead.

As presentations at this conference have indicated, these kinds of systems are starting to improve quality and quantity of education internationally, as well as at national and local levels, and the people who can push this movement along are at this conference. If not you, Who? If not now, When?

Further information: Dr James C. Lange, Golden West Network, 96

Wanneroo Road, Tuart Hill, 6060, Western Australia. Tel: (61-9) 344 3553,

Fax: (61-9) 3495555

Based on a paper presented at EdTech'86, International Educational

Technology Conference and Exhibition, University of Western Australia,

Perth, 2-5 December 1986.

Please cite as: Lange, J. C. (1987). Talk-back television: The Western

Australian experience. Australian Journal of Educational Technology, 3(1), 37-

44. http: / / www.ascilite.org.au/ajet/ajet3/lange.html 